\title{
(6) OPEN ACCESS \\ Mental health status and gender as risk factors for onset of physical illness over 10 years
}

\author{
Flora I Matheson, ${ }^{1,2,3}$ Katherine L W Smith, ${ }^{1}$ Rahim Moineddin, ${ }^{2,4}$ James R Dunn, ${ }^{1,2,5}$ \\ Richard H Glazier ${ }^{1,2,3,4}$
}

${ }^{1}$ Centre for Research on Inner City Health at The Keenan Research Centre in the Li Ka Shing Knowledge Institute of St. Michael's Hospital, Toronto, Ontario, Canada

${ }^{2}$ Institute for Clinical Evaluative Sciences, Toronto, Ontario, Canada

${ }^{3}$ Dalla Lana School of Public Health, University of Toronto, Toronto, Ontario, Canada ${ }^{4}$ Department of Family and Community Medicine, University of Toronto, Toronto, Ontario, Canada

${ }^{5}$ Department of Health, Aging and Society, McMaster University, Hamilton, Ontario, Canada

\section{Correspondence to} Dr Flora I Matheson, Centre for Research on Inner City Health, St. Michael's Hospital, 30 Bond Street, Toronto, Ontario, Canada M5B 1W8; mathesonf@smh.ca

Received 7 May 2013 Revised 2 July 2013 Accepted 8 August 2013 Published Online First 6 September 2013

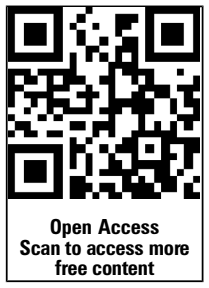

To cite: Matheson $\mathrm{Fl}$, Smith KLW, Moineddin $\mathrm{R}$ et al. J Epidemiol Community Health 2014;68:64-70.

\section{ABSTRACT}

Background There is a growing interest in understanding the connection between mental illness (MI) and the onset of new physical illnesses among previously physically healthy individuals. Yet the role of gender is often forgotten in research focused on comorbidity of health problems. The objective of this study was to examine gender differences in the onset of physical illness in a cohort of respondents who met criteria for MI compared with a control cohort without mental health problems.

Methods This cohort study, conducted in Ontario, Canada, used a unique linked dataset with information from the 2000-2001 Canadian Community Health Survey and medical records ( $n=15$ 902). We used adjusted Cox proportional survival analysis to examine risk of onset of four physical health problems (chronic obstructive pulmonary disorder, asthma, hypertension and diabetes) for those with and without baseline $\mathrm{MI}$ across a 10-year period (2002-2011) among respondents aged $18-74$ years. We controlled for socioeconomic and health indicators associated with health.

Results The incidence of physical illness in the MI cohort was $28.5 \%$ among women and $29.9 \%$ among men $(p=0.85)$ relative to controls $(23.8 \%$ and $24 \%$, respectively; $\mathrm{p}=0.48)$. Women in the $\mathrm{Ml}$ cohort developed secondary physical health problems a year earlier than their male counterparts $(p=0.002)$. Findings from the Cox proportional survival regression showed that women were at $14 \%$ reduced risk of developing physical illness, meaning that men were more disadvantaged ( $\mathrm{HR}=0.89, \mathrm{Cl} 0.80$ to 0.98 ). Those in the $\mathrm{Ml}$ cohort were at 10 times greater risk of developing a secondary physical illness over the 10-year period $(H R=1.10, \mathrm{Cl} 0.98$ to 1.21). There was no significant interaction between gender and $\mathrm{MI}$ cohort $(\mathrm{HR}=1.05, \mathrm{Cl}$ 0.85 to 1.27 ).

Conclusions Policy and clinical practice have to be sensitive to these complex-needs patients. Genderspecific treatment and prevention practices can be developed to target those at higher risk of multiple health conditions.

\section{INTRODUCTION}

An estimated $25-30 \%$ of the population in the USA lives with a mental health disorder in any given year. ${ }^{1}$ People suffering from mental illness (MI) experience increased rates of comorbid physical illness ${ }^{2} 3$ and increased mortality from natural causes, ${ }^{3}$ suggesting poor physical health over a sustained period of time. Two studies found that over $65 \%$ of adults with any mood and substance use disorder had at least one additional chronic condition compared with $40-50 \%$ of age-matched adults with no mental disorder. ${ }^{4}$

Recent reviews show an elevated prevalence of metabolic syndrome, diabetes, hypertension, cardiovascular, viral and respiratory diseases in people with serious MI. ${ }^{2}$ 6-8 Compared with the general population and matched healthy controls, people with depression have a higher prevalence of diabetes, asthma, gastric ulcers, rhinitis, hypertension, thyroid disease and osteoarthritis. ${ }^{9} 10$

There is a growing interest in understanding links between MI and onset of incident physical illnesses among previously physically healthy individuals. Holahan et $a l^{11}$ found that clinically depressed people were two-thirds more likely to experience incident physical illness over a 10 -year follow-up period compared with community controls (after controlling for prior illness). For example, depression is associated with incident diabetes, chronic bronchitis/emphysema, hypertension, migraines, heart disease, arthritis, asthma and back pain. ${ }^{12-14}$

The role of gender in comorbidity of illness has not been explored extensively in the literature; typically, gender is included as a covariate in regression models. Yet gender is a key element in comorbid development of disease. For instance, while men and women with mood disorders receive different types of comorbid diagnoses, little research has focused on identifying the gender-related aetiological and treatment implications of these phenomenological differences. ${ }^{15}{ }^{16}$ Furthermore, if comorbidity reflects biological factors that are shared with mood disorders, then differences in the types of comorbid conditions expressed (eg, depression, drug abuse) may reflect socialised differences.

Courtenay $^{17}$ argues that men more so than women engage in risk-taking behaviours like driving under the influence and engaging with multiple sexual partners. Women experience more psychological distress deriving from lower social status and multiple role performances. ${ }^{18-20}$ Women have more comorbid lifetime diagnoses, especially in combination with depression, yet depression secondary to substance abuse appears to be more common among men. ${ }^{21}$ To the extent that differences in the patterning, nature and chronicity of comorbid disorders exist between men and women, these will have important consequences for successful treatment. McCusker et $a l^{22}$ found that being a woman was associated with a worse physical health score over a 1-year period, whereas Holahan et $a l^{11}$ found that sex was not associated with incident physical illness over 10 years. Arthritis incidence has been associated with being a woman. ${ }^{14}$ 
Using a novel methodology that includes administrative and national survey data, this study specifically adds to the small body of research on gender-based analysis on comorbid MI and physical illness by examining the association between mental health problems and incident onset of any one of four physical health illnesses (asthma, hypertension, chronic obstructive pulmonary disorder (COPD) and diabetes) over a 10-year period. We examine: (1) whether those with a baseline mental health problem (excluding people with baseline physical health problems) are at greater risk of developing incident physical illness relative to those without baseline mental health problems over a 10-year follow-up period, and; (2) whether there is a gender difference in the risk of incident onset of physical illness.

\section{METHODS}

\section{Data sources}

Ethics approval was obtained from the St Michael's Hospital and Sunnybrook Health Sciences Centre Research Ethics Review Boards. The study was conducted in the province of Ontario in Canada where there is universal medical coverage, whereby every permanent resident of Ontario is eligible for healthcare with no deductibles or copayments.

Data for this cohort study were available from the Institute for Clinical Evaluative Sciences (ICES). Mental and physical health information, as well as sociodemographic characteristics, was obtained from the Ontario Linking file of the Canadian Community Health Survey (CCHS) 1.1 collected in the 20002001 cycle. This is the only cycle that provides depression data for all individuals in Ontario. CCHS is a nationally representative cross-sectional survey designed to collect information on health determinants, outcomes and health service utilisation among non-institutionalised Canadians aged 12 years and over. The linking file includes all respondents from Ontario who, when surveyed, agreed to have their responses linked to administrative data for research purposes. The Ontario response rate was $82 \%$ (39 278), of which $90.8 \%$ of respondents agreed to linkage. The CCHS and the administrative data were linked using an encrypted ID; 92.1\% were successfully linked giving a sample of 32848 . Exclusions included records with missing values (with the exception of income, missing values ranged from 1\%to 10\%), respondents younger than 18 and older than 74 years, as well as respondents with baseline physical health problems (details below), leaving a final sample of 15902 (5065 in the MI cohort and 10837 in the control cohort). Sensitivity analysis revealed little difference between cases deleted and those retained.

Additional mental and physical health data were obtained from administrative sources: the Ontario Health Insurance Plan (OHIP), the Discharge Abstract Database (DAD) and the Ontario Mental Health Reporting System (OMHRS). The OHIP data contain physician visit and procedure claims which include service and diagnostic codes, fees for service provided, and date of service. DAD contains up to 16 diagnoses and 12 procedures for acute care hospitalisations and day procedures across Ontario. OMHRS provides data on patients in adult designated inpatient mental health beds, including beds in general, provincial psychiatric and specialty psychiatric facilities. Eligibility for health services and death data was extracted from the Registered Persons Data Base (RPDB). This is Ontario's healthcare registry which provides information on age, sex, postal code, eligibility and death data. Adults were eligible for inclusion in the study if they had a valid health card number at the index date of the study (2000-2001) and if the date of death was after the study start date.

\section{MI cohort}

The MI cohort was defined using the CCHS and the administrative data. It included CCHS respondents who self-reported depression, consulted a mental health professional or felt they needed, but did not receive, treatment for an emotional problem in the 12 months prior to the interview. In addition, CCHS respondents who did not self-report one of the above criteria for a mental health condition, but who met the validated cohort criteria for mental health in the administrative data (eg, a respondent saw a physician for mental health reasons), were also included in the MI cohort. ${ }^{23}$ An ambulatory mental health visit reflects physician claims that include a service and a diagnostic code. Physicians assign a mental health (a visit exceeding $20 \mathrm{~min}$ ) or a general service code (shorter visits), which is a three-digit shortened version of the codes provided in the International Classification of Diseases reflecting the most responsible reason for any visit. ${ }^{23}$

In CCHS, depression was assessed using the Composite International Diagnostic Interview Short Form for Major Depression (CIDI-SF). CIDI-SF is a validated epidemiological tool to identify depression which is used in non-clinical settings. $^{24}$ In this project, patients regarded as having major depression were those reporting a total of four or more depressive symptoms, including depressed mood or loss of interest. The instrument's validation data suggest that $81.25 \%$ of patients meeting these criteria would have major depression according to the full CIDI. ${ }^{25}$

To ensure that physical health conditions did not develop prior to or concurrently with mental health conditions, we excluded anyone who self-reported or had physician visits or hospitalisations for asthma, hypertension, diabetes or COPD during the 2 years prior to the CCHS interview.

A control cohort was created for comparison and comprised respondents who did not meet the criteria for inclusion in the MI cohort, as well as people who did not have physical health conditions at baseline (assessed through self-report and administrative data).

\section{Physical illness}

Administrative data were used to determine the onset of incident physical illness (asthma, hypertension, diabetes and COPD). We used four disease-specific ICES-validated cohort databases to identify physical illness in the 10-year follow-up period. The event or first episode was defined as the first diagnosis for any of the co-occurring health conditions in OMHRS (inpatient mental health), OHIP (physician visits/claims) or DAD (hospitalisations).

In the Ontario Asthma Database, a patient is classified as asthmatic if she/he had one hospital admission with an asthma diagnosis or two OHIP claims with asthma diagnosis within 2 years. $^{26}$ The asthma algorithm was highly sensitive (84\%) and specific (76\%) among adults aged $18+$ years. In the Ontario COPD Database, a patient is said to have COPD if she/he had one COPD diagnosis in OHIP or DAD or OMHRS. ${ }^{27}$ The COPD algorithm was highly sensitive (85\%) and specific (78.4\%). The Ontario Hypertension Database identifies cases as present if an individual had one hospital admission with a hypertension diagnosis, or an OHIP claim with a hypertension diagnosis followed within 2 years by either an OHIP claim or a hospital admission with a hypertension diagnosis. ${ }^{28}$ The hypertension algorithm was $72 \%$ sensitive and $95 \%$ specific. The Ontario Diabetes Database identifies individuals with diabetes as those with at least one hospitalisation or at least two claims for 
physicians' services (within 2 years). This algorithm was found to be highly sensitive (86\%) and specific (97\%). ${ }^{29}$

\section{Control variables}

We selected control variables known to be associated with gender differences in health ${ }^{30}{ }^{31}$ : demographic (age, gender, marital status and ethno-racial origin), socioeconomic characteristics (highest level of educational attainment and annual household income) and health behaviours (smoking and drinking status, perceived stress level and activity level). Leisure-time physical activity was calculated based on the frequency and duration of each activity within the 3 months prior to being surveyed (energy expenditure, EE) and its value of metabolic energy cost. Using predefined categories from Statistics Canada, EE below $1.5 \mathrm{kcal} / \mathrm{kg} /$ day was considered to be physically inactive; respondents with EE values between 1.5 and $2.9 \mathrm{kcal} /$ $\mathrm{kg} /$ day were considered to be moderately active, whereas respondents with $\mathrm{EE}$ values of $3 \mathrm{kcal} / \mathrm{kg} /$ day or greater were considered to be active. ${ }^{32}$ For this analysis, moderately active and active were combined. Heavy drinking was defined as 14 or more weekly drinks for men and 10 or more weekly drinks for women. Current smokers were those who reported being a daily or occasional smoker. Respondents reported their perceived stress based on the question: "Thinking about the amount of stress in your life, would you say that most days are (not at all stressful, not very stressful, a bit stressful, quite a bit stressful, or extremely stressful)?" Those reporting "quite a bit stressful" or "extremely stressful" were categorised as having "high stress." Otherwise, they were categorised as having "low stress" (71\%).

The sample was relatively disease free with respect to the four selected physical illnesses but may have had other types of health issues. We adjusted for this possibility using resource utilisation bands (RUBs) and aggregated diagnosis groups (ADGs) which were generated using the Johns Hopkins Adjusted Clinical Groups System, which is a method that uses administrative claims-based diagnosis data to adjust for the morbidity burden of populations. ${ }^{33}$ RUBs are constructed using age, sex and mixtures of diagnoses associated with the expected intensity of resource use. RUB values are categorised as low (0 and 1), intermediate (2 and 3 ) and high (4 and 5) with higher values reflecting a higher burden of illness on the healthcare system. ADGs represent a compilation of diagnostic codes similar in severity and expected persistence over time. They reflect comorbidity and additional health burden on top of that reflected by RUBs. ADGs were categorised as low (0-1), moderate (2-5) and high (6-34). ADGs and RUBs were calculated in the period 2 years prior to the CCHS interview.

\section{Statistical approach}

We first compared the baseline characteristics of the mental health and control cohorts. We show unweighted sample numbers and weighted proportions; the latter were generated using the survey weights provided by Statistics Canada.

The Cox proportional hazard regression analysis was conducted to estimate the effect of gender and mental health status on physical illness while adjusting for the effects of other covariates. This method allows for the modelling of the length of time until the occurrence of an event-onset of a physical health problem-during the 10-year follow-up period spanning 20022011. Survival curves for the time to first occurrence of the secondary health problem were obtained with the Kaplan-Meier method.
We first developed a model with the main effects of gender and mental health status without covariates adding these in the second phase of modelling. We then produced an adjusted and stratified survival model from which we produced the probabilities of survival by gender and mental health status. Finally, we tested for the significance of the interaction between gender and mental health status. Tests for proportionality and interactions with time were tested and found to be not significant. Data publication guidelines of Statistics Canada were followed throughout the analysis. SAS V.9.2 (SAS Institute Inc, Cary, North Carolina, USA) was used for data manipulation and statistical analysis.

\section{RESULTS}

Table 1 provides descriptive statistics for the sample (columns $2 / 3$ ) by cohort. Women predominated in the MI cohort $(63.1 \%)$ with a more even gender distribution among controls. More respondents in the MI cohort were in the lower income bracket, were stressed, smoked, reported disability, and had higher scores on measures of morbidity and comorbidity (ADGs and RUBs) than controls (columns 2/3, table 1 ).

The overall incidence of physical health problems in the sample was 26.9\% (control: 23.9\%; 29\% MI cohort). For controls, $49.7 \%$ had mental and physical health problems at follow-up. Table 1 also shows the percentage/number of respondents by cohort that developed a physical health problem by the end of the follow-up period (columns 4/5). More men $(29.9 \%)$ and women $(28.5 \%, \mathrm{p}=0.85)$ in the MI cohort had a subsequent physical health problem than their counterpart controls ( $24 \%$ vs $23.8 \%$, respectively; $\mathrm{p}=0.48$ ). Risk factors for developing a subsequent physical health problem among those in the MI cohort relative to controls included being younger (age 1840), of lower socioeconomic status (no high school diploma, low income), single, non-white, with higher experienced stress, smokers, heavy drinkers, and additional morbidities and comorbidities (ADGs and RUBs). For example, the percentage of those aged 18-29 years (12.5\%) with a mental health problem was twice as high as those in the same age group without a mental health problem (6.8\%).

There was little difference in the median onset of a physical health problem between the mental health (57.7 months) and control (57.9 months) cohorts. In the MI cohort, the median time to onset of a physical health problem was 60.7 months (5.1 years) for men and 51.6 months for women (4.3 years; $\mathrm{p}=0.002)$; among controls, there was no statistical difference in months to onset (58.3 vs 57.2).

Table 2 shows the adjusted HRs from the Cox proportional regression. Women were at a $14 \%$ reduced risk of developing a physical health problem when compared with men $(\mathrm{HR}=0.89$, CI 0.80 to 0.98 ) regardless of the presence of a baseline mental health problem. In an unadjusted model, women were not at increased risk of onset of physical illness $(\mathrm{HR}=1.02$, CI 0.92 to 1.11). There was a non-significant trend suggesting that those in the MI cohort were at increased risk of developing incident physical health problems $(\mathrm{HR}=1.10 ; \mathrm{p}=0.087)$. In an unadjusted model, those in the MI cohort were at increased risk of onset of physical illness $(H R=1.23$, CI 1.14 to 1.38$)$. To further explore gender differences in health, we show the adjusted probability of onset of physical illness for men and women in each cohort (figure 1). The probability of onset of physical illness is fairly similar across groups with risk increasing over time for all groups. While the groups had similar risk profiles, women with no mental health problems had the lowest risk profile. We tested for an interaction between gender and 
Table 1 Descriptive statistics for mental health and control cohorts by sociodemographic characteristics and health indicators

\begin{tabular}{|c|c|c|c|c|}
\hline & \multicolumn{2}{|l|}{ Sample characteristics $(\%, \mathrm{~N})$} & \multicolumn{2}{|c|}{ Incidence of physical health problem $(\%, \mathrm{~N})$} \\
\hline & Mental illness cohort $(n=5065)$ & Control cohort $(n=10$ 837) & Mental illness cohort $(n=5065)$ & Control cohort $(n=10837)$ \\
\hline \multicolumn{5}{|l|}{ Gender } \\
\hline Female & $63.1(3375)$ & $45.6(5235)$ & $28.5(1008)$ & $23.8(1291)$ \\
\hline Male & $36.9(1690)$ & $54.4(5602)$ & $29.9(538)$ & $24.0(1442)$ \\
\hline \multicolumn{5}{|l|}{ Age group } \\
\hline $18-29$ & $25.1(1089)$ & $26.6(2494)$ & $12.5(133)$ & $6.8(175)$ \\
\hline 30-39 & $28.6(1450)$ & $26.6(2816)$ & $25.0(342)$ & $17.5(458)$ \\
\hline $40-49$ & $25.9(1339)$ & $24.9(2654)$ & $33.9(450)$ & $28.8(730)$ \\
\hline $50-59$ & $13.4(740)$ & $12.8(1572)$ & 39.9 (338) & $42.8(655)$ \\
\hline $60-74$ & $7.1(447)$ & $9.1(1301)$ & $65.4(283)$ & $52.9(715)$ \\
\hline \multicolumn{5}{|l|}{ Educational attainment } \\
\hline No high school diploma & $14.9(876)$ & $12.7(1762)$ & $36.6(340)$ & $33.3(596)$ \\
\hline High school diploma & 31.7 (1574) & $34.2(3525)$ & $26.2(449)$ & $21.5(796)$ \\
\hline Postsecondary education & $53.4(2615)$ & $53.2(5550)$ & $28.6(757)$ & $23.2(1341)$ \\
\hline \multicolumn{5}{|l|}{ Annual household income } \\
\hline Under \$C20 000 & $8.4(661)$ & $4.4(703)$ & $31.2(227)$ & 27.1 (194) \\
\hline$\$ C 20000-\$ C 39000$ & $15.1(916)$ & $12.3(1685)$ & $34.0(309)$ & $28.9(485)$ \\
\hline$\$ C 40000-\$ C 59000$ & $16.8(888)$ & $15.3(1822)$ & $32.4(281)$ & $23.6(440)$ \\
\hline$\$ C 60000-\$ C 79000$ & $17.0(778)$ & $17.6(1894)$ & $26.7(216)$ & $24.5(462)$ \\
\hline$\$ C 80000+$ & $26.2(1054)$ & $32.1(2925)$ & $26.6(274)$ & $22.8(677)$ \\
\hline Missing & $16.6(768)$ & $18.3(1808)$ & $26.0(239)$ & $21.5(475)$ \\
\hline \multicolumn{5}{|l|}{ Marital status } \\
\hline Separated/divorced/widowed & $12.6(1046)$ & $7.2(1240)$ & $38.4(424)$ & $32.9(460)$ \\
\hline Single & $27.0(1266)$ & $26.8(2721)$ & $19.3(248)$ & $10.7(339)$ \\
\hline Married/common law & $60.3(2753)$ & $66.0(6876)$ & $31.4(874)$ & 28.3 (1934) \\
\hline \multicolumn{5}{|l|}{ Ethno-racial origin } \\
\hline White & $83.9(4642)$ & 82.9 (9932) & $29.0(1423)$ & 24.5 (2534) \\
\hline Non-white & $16.1(423)$ & $17.1(905)$ & $29.2(123)$ & $21.2(199)$ \\
\hline \multicolumn{5}{|l|}{ Self-perceived stress } \\
\hline Moderate/high & $38.6(2021)$ & $20.5(2184)$ & $30.9(642)$ & $25.8(556)$ \\
\hline Low/none & $61.4(3044)$ & $79.5(8653)$ & $27.8(904)$ & $23.5(2177)$ \\
\hline \multicolumn{5}{|l|}{ Current smoker } \\
\hline Yes & $32.6(1854)$ & $26.6(3084)$ & $30.2(590)$ & $23.6(755)$ \\
\hline No & $67.4(3211)$ & $73.4(7753)$ & $28.4(956)$ & 24.1 (1978) \\
\hline \multicolumn{5}{|l|}{ Heavy drinker } \\
\hline Yes & $2.8(150)$ & $3.6(427)$ & $31.7(36)$ & $23.1(108)$ \\
\hline No & $97.2(4915)$ & $96.4(10410)$ & $28.9(1510)$ & $24.0(2625)$ \\
\hline \multicolumn{5}{|l|}{ Activity } \\
\hline Active & $21.6(1157)$ & $22.6(2714)$ & $23.1(294)$ & $20.8(603)$ \\
\hline Non-active & 78.4 (3908) & $77.4(8123)$ & $30.6(1252)$ & $24.8(2130)$ \\
\hline \multicolumn{5}{|l|}{ Disability } \\
\hline Often & $11.2(713)$ & $5.2(707)$ & $35.6(273)$ & $37.7(262)$ \\
\hline Some & $16.0(847)$ & $11.1(1321)$ & $36.0(308)$ & $30.5(432)$ \\
\hline Never & $72.9(3505)$ & $83.7(8809)$ & 26.5 (965) & $22.2(2039)$ \\
\hline \multicolumn{5}{|l|}{ Rural } \\
\hline Yes & $11.6(816)$ & 15.9 (2427) & $26.9(255)$ & $24.7(640)$ \\
\hline No & $88.4(4249)$ & $84.1(8410)$ & $29.3(1291)$ & $23.8(2093)$ \\
\hline \multicolumn{5}{|c|}{ Number of aggregated diagnosis groups } \\
\hline Low $(0-1)$ & $6.5(321)$ & $26.4(2991)$ & $25.0(72)$ & $19.6(622)$ \\
\hline Medium (2-5) & $42.2(2110)$ & $53.8(5837)$ & $25.0(553)$ & $23.5(1438)$ \\
\hline High (6-34) & $51.3(2634)$ & $19.8(2009)$ & $32.8(921)$ & $30.9(673)$ \\
\hline \multicolumn{5}{|l|}{ Resource utilisation bands } \\
\hline Low (0-1) & $4.2(194)$ & $22.6(2526)$ & $24.1(43)$ & $18.1(510)$ \\
\hline Medium (2) & $12.2(587)$ & $27.7(2979)$ & $22.3(122)$ & $20.5(618)$ \\
\hline High (3) & $64.5(3264)$ & 41.5 (4474) & $29.0(1038)$ & $29.2(1373)$ \\
\hline Very high (4-5) & $19.1(1020)$ & $8.1(858)$ & $34.3(343)$ & $25.2(232)$ \\
\hline
\end{tabular}


Table 2 Adjusted Cox proportional regression model showing HRs for development of physical illness among the mental health and control cohorts by sociodemographic characteristics and health indicators

\begin{tabular}{|c|c|c|c|}
\hline & HR & $95 \% \mathrm{Cl}$ & $p$ Value \\
\hline \multicolumn{4}{|l|}{ Gender } \\
\hline Female & 0.89 & (0.80 to 0.98$)$ & 0.024 \\
\hline Male & 1.00 & & \\
\hline Mental illness cohort & 1.10 & (0.98 to 1.21 ) & 0.087 \\
\hline \multicolumn{4}{|l|}{ Age group } \\
\hline $18-29$ & 0.11 & (0.09 to 0.14 ) & 0.000 \\
\hline $30-39$ & 0.26 & (0.22 to 0.30$)$ & 0.000 \\
\hline $40-49$ & 0.44 & (0.37 to 0.50$)$ & 0.000 \\
\hline $50-59$ & 0.65 & (0.55 to 0.74 ) & 0.000 \\
\hline $60-74$ & 1.00 & & \\
\hline \multicolumn{4}{|l|}{ Educational attainment } \\
\hline No high school diploma & 1.21 & (1.06 to 1.36$)$ & 0.003 \\
\hline High school diploma & 1.02 & (0.91 to 1.13 ) & 0.691 \\
\hline Postsecondary education & 1.00 & & \\
\hline \multicolumn{4}{|l|}{ Annual household income } \\
\hline Under \$C20 000 & 1.13 & (0.88 to 1.37 ) & 0.281 \\
\hline$\$ C 20000-\$ C 39000$ & 1.18 & (0.98 to 1.38 ) & 0.051 \\
\hline$\$ C 40000-\$ C 59000$ & 1.07 & (0.90 to 1.24 ) & 0.409 \\
\hline$\$ C 60000-\$ C 79000$ & 1.03 & (0.88 to 1.18 ) & 0.671 \\
\hline Missing & 0.97 & (0.82 to 1.12 ) & 0.698 \\
\hline$\$ C 80000+$ & 1.00 & & \\
\hline \multicolumn{4}{|l|}{ Marital status } \\
\hline Separated/divorced/widowed & 0.93 & (0.81 to 1.04 ) & 0.220 \\
\hline Single & 0.89 & (0.73 to 1.06$)$ & 0.218 \\
\hline Married/common law & 1.00 & & \\
\hline \multicolumn{4}{|l|}{ Ethno-racial origin } \\
\hline White & 0.91 & (0.73 to 1.08$)$ & 0.300 \\
\hline Non-white & 1.00 & & \\
\hline \multicolumn{4}{|l|}{ Self-perceived stress } \\
\hline Moderate/high & 1.10 & (0.99 to 1.21$)$ & 0.057 \\
\hline Low/none & 1.00 & & \\
\hline \multicolumn{4}{|l|}{ Current smoker } \\
\hline Yes & 1.21 & (1.08 to 1.34$)$ & 0.000 \\
\hline No & 1.00 & & \\
\hline \multicolumn{4}{|l|}{ Heavy drinker } \\
\hline Yes & 1.19 & (0.89 to 1.49 ) & 0.178 \\
\hline No & 1.00 & & \\
\hline \multicolumn{4}{|l|}{ Activity } \\
\hline Active & 0.88 & (0.92 to 0.97 ) & 0.017 \\
\hline Non-active & 1.00 & & \\
\hline \multicolumn{4}{|l|}{ Disability } \\
\hline Often & 1.15 & (0.97 to 1.33 ) & 0.038 \\
\hline Some & 1.13 & (1.00 to 1.26$)$ & 0.087 \\
\hline Never & 1.00 & & \\
\hline \multicolumn{4}{|l|}{ Rural } \\
\hline Yes & 0.96 & (0.86 to 1.05$)$ & 0.402 \\
\hline No & 1.00 & & \\
\hline \multicolumn{4}{|c|}{ Number of aggregated diagnosis groups } \\
\hline High (6-34) & 1.25 & (0.93 to 1.57 ) & 0.078 \\
\hline Medium (2-5) & 1.01 & (0.79 to 1.23 ) & 0.923 \\
\hline Low $(0-1)$ & 1.00 & & \\
\hline \multicolumn{4}{|l|}{ Resource utilisation bands } \\
\hline Very high (4-5) & 1.30 & (0.95 to 1.65 ) & 0.053 \\
\hline High (3) & 1.29 & (0.99 to 1.60 ) & 0.033 \\
\hline Medium (2) & 1.18 & (0.93 to 1.43 ) & 0.133 \\
\hline Low (0-1) & 1.00 & & \\
\hline
\end{tabular}

mental health status, but there was no significant effect (data not shown).

\section{DISCUSSION}

This study examined comorbid mental health problems and incident onset of any one of four physical illnesses (asthma, hypertension, COPD and diabetes) over a 10-year period. We used pre-existing validated cohorts for all illnesses. At the end of the follow-up period, the overall incidence of physical illness was $29 \%$ in the MI cohort and $23.9 \%$ in controls. There are no direct comparisons to these figures in the literature as this study looked at the onset of physical illness over time and in the presence of mental health problems. Cross-sectional studies looking at the prevalence of physical health conditions in mental health populations have reported higher prevalence rates (67-68\%). ${ }^{4}$

The median risk of onset of physical illness was 4.8 years overall. In the MI cohort, there appears to be a gender difference in timing of onset, with women (4.3 years) having a lower median onset of physical illness than men (5.1 years). About half of the sample did not experience physical illness for an extended period of time after self-reported mental health problems.

Survival analysis showed that women had a $14 \%$ reduced risk of onset of physical illness (in other words, men were disadvantaged in this respect). Social and biological explanations have been proposed to explain gender differences in morbidity and mortality. Courtenay ${ }^{34}$ argues that men conceal vulnerability; they are much more likely to conceal pain and illness than women. ${ }^{35}$ Research suggests that social roles help to explain gender differences in health specifically in the context of male biological disadvantage. For example, men experience more lifetime serious disability and disease that can shorten their lives. On the other hand, women tend to have more symptoms with less serious problems. ${ }^{35} 36$

There was a non-significant trend $(\mathrm{p} \leq 0.10)$ suggesting that people with a mental health problem were more likely to develop incident physical illness, a finding supported by previous research. ${ }^{3} 11$ There were no significant differences in risk of onset of incident physical illness for men and women in the mental health or control cohorts; rather, risk increased over time for all groups. Women without mental health problems had the lowest risk profile.

The lack of a significant gender-mental health interaction may reflect the use of the validated but broad definition of mental health. In an effort to provide similarly broad definitions of mental health from the medical records and the survey data, we defined MI as those who reported depression, who consulted a mental health professional in the 12 months prior to the interview and as those who needed but did not receive mental healthcare. It is possible that a respondent only consulted a healthcare professional once during the 12-month period. Steele et al found several problems with the mental health codes in Ontario medical data. First, mental health services offered as part of shorter medical visits are not always assigned service codes specific to mental health. Second, they found poor sensitivity for narrow mental health service codes such as depression. ${ }^{23}$ The lack of consistency in coding of mental health visits in the medical data limits our ability to examine specific mental health diagnoses.

Previous research which has explored comorbidity between MI and physical illness has been concerned overwhelmingly with physical illness as a predictor of incident MI, especially depressive reactions. ${ }^{11-14}$ The potential role of MI (and not just depression) in predicting incident physical illness is 


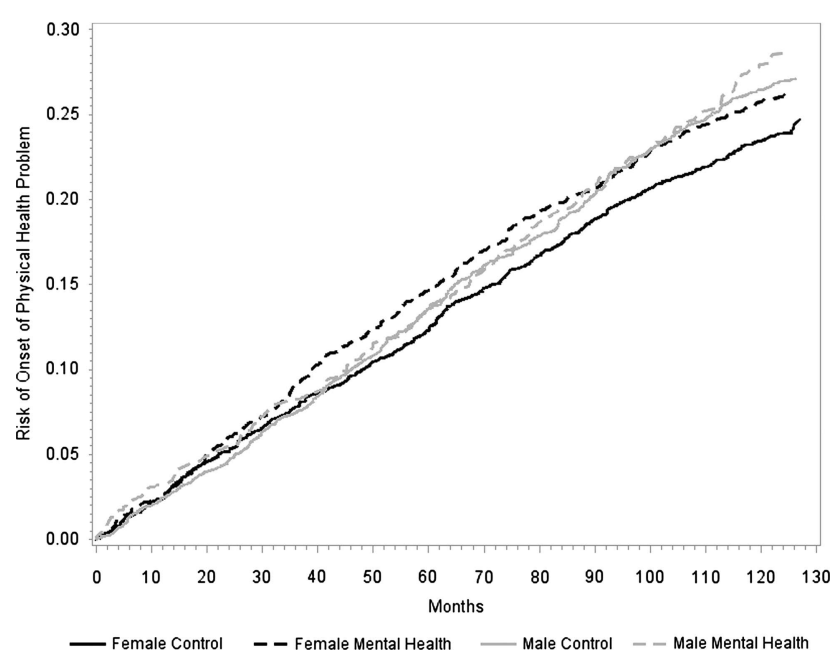

Figure 1 Probability of onset of physical health problems (20012011) by gender and cohort.

understudied. ${ }^{11}{ }^{14}$ Furthermore, the majority of previous research on MI and incident physical illness has involved specific physical illnesses ${ }^{12} 37 \quad 38$ rather than multiple physical health problems and has largely ignored issues related to comorbidity and gender.

Recall bias may influence accuracy of self-report data, especially among those with MI. Social desirability, impression management and self-deception can be problems when exploring socially 'sensitive' and highly stigmatised medical conditions. ${ }^{39}$ Nonetheless, the CCHS sample is representative of the population and provides a highly valuable depiction of these populations, including those with lesser disease severity who are inherently hard to identify. The study is restricted to respondents in Ontario, Canada and therefore is only generalisable to the Ontario population. In addition, we captured a select set of physical health outcomes (asthma, hypertension, COPD and diabetes) that had been subject to validation. Follow-up research might look at an expanded list of chronic physical conditions. The physician claim codes do not capture alternate payment plans, and therefore physicians in community health centres are absent from the data. At the time of the study, non-fee-for-service utilisation represented a small minority of primary care visits and there were very few specialist visits (less than $6 \%) .^{40}$

The study demonstrated a trend effect $(p=0.087)$ between MI and incident physical illness within a 10 -year period. Findings for gender were more subtle but suggested a trend with men more likely to experience incident physical illness in the same time period; however, women with MI became physically ill a year earlier than men. Given the small body of literature on the topic, this paper suggests the need for more research using more specific measures of MI to fully understand gender and comorbidity.

Sensitivity in policy and clinical practice to complex-needs patients might mean developing gender-specific treatment and prevention practices as these patients are not easily managed within short appointments. Time constraints often force physicians to address the most salient health problem (eg, depression) to the detriment of preventive procedures (eg, blood pressure testing). Policy initiatives aimed at changes to billing practices are necessary to enable physicians to spend more time with these patients, which in the long term will help to reduce health system costs.

\section{What is already known on this subject}

- Gender is a complicating factor in comorbid illness, yet its role in this relationship has not been explored extensively in the literature. Only a few studies have looked at gender in relation to mental illness and onset of incident physical illness, and the results have been contradictory.

\section{What this study adds}

- The study demonstrated a relationship between mental illness (MI) and incident physical illness within a 10-year period. Those in the Ml cohort were at 10 times greater risk of developing a secondary physical illness over the 10-year period.

- Findings for gender were subtle but suggested a trend with men more likely to experience incident physical illness in the same time period; however, women with Ml became physically ill a year earlier than men.

- Given the small body of literature on the topic, this paper suggests the need for more research using better measures of MI to fully understand gender and comorbidity.

Correction notice This paper has been corrected since it was published online. An acknowledgement statement has been added.

Acknowledgements This study was supported by the Centre for Research on Inner City Health (CRICH) and the Institute for Clinical Evaluative Sciences (ICES). $\mathrm{CRICH}$ is part of the Keenan Research Centre in the Li Ka Shing Knowledge Institute of St. Michael's Hospital. ICES is funded by an annual grant from the Ontario Ministry of Health and Long-Term Care (MOHLTC). The opinions, results and conclusions reported in this paper are those of the authors and are independent from the funding sources. No endorsement by CRICH, ICES or the Ontario MOHLTC is intended or should be inferred.

Contributors FIM, RM and KLWS were responsible for data analysis with intellectual contribution from RHG and JRD. KLWS and FIM drafted the article. All authors contributed to the conception and design of the paper, interpretation of data, critical revisions contributing to the intellectual content and approval of the final version of the manuscript.

Funding This research was supported by the Social Sciences and Humanities Research Council of Canada, Standard Research Grant No. 410-2009-1894.

\section{Competing interests None.}

Ethics approval St Michael's Hospital Ethics Review Board and Sunnybrook Health Sciences Research Ethics Board.

Provenance and peer review Not commissioned; externally peer reviewed.

Open Access This is an Open Access article distributed in accordance with the Creative Commons Attribution Non Commercial (CC BY-NC 3.0) license, which permits others to distribute, remix, adapt, build upon this work non-commercially, and license their derivative works on different terms, provided the original work is properly cited and the use is non-commercial. See: http://creativecommons.org/ licenses/by-nc/3.0/

\section{REFERENCES}

1 Kessler RC, Chiu WT, Demler O, et al. Prevalence, severity, and comorbidity of 12-month DSM-IV disorders in the National Comorbidity Survey Replication. Arch Gen Psychiatry 2005;62:617-27.

2 De HM, Correll CU, Bobes J, et al. Physical illness in patients with severe mental disorders. I. Prevalence, impact of medications and disparities in health care. World Psychiatry 2011;10:52-77.

3 Osborn DP. The poor physical health of people with mental illness. West J Med 2001;175:329-32.

4 Levinson D, Karger CJ, Haklai Z. Chronic physical conditions and use of health services among persons with mental disorders: results from the Israel National Health Survey. Gen Hosp Psychiatry 2008;30:226-32. 
5 Scott KM, Von KM, Alonso J, et al. Mental-physical co-morbidity and its relationship with disability: results from the World Mental Health Surveys. Psychol Med 2009:39:33-43.

6 De HM, Schreurs V, Vancampfort D, et al. Metabolic syndrome in people with schizophrenia: a review. World Psychiatry 2009;8:15-22.

7 Leucht S, Burkard T, Henderson J, et al. Physical illness and schizophrenia: a review of the literature. Acta Psychiatr Scand 2007;116:317-33.

8 Osborn DP, Wright CA, Levy G, et al. Relative risk of diabetes, dyslipidaemia, hypertension and the metabolic syndrome in people with severe mental illnesses: systematic review and metaanalysis. BMC Psychiatry 2008;8:84.

9 Farmer A, Korszun A, Owen MJ, et al. Medical disorders in people with recurrent depression. Br J Psychiatry 2008;192:351-5.

10 Katon WJ. The comorbidity of diabetes mellitus and depression. Am J Med 2008:121(11 Suppl 2):S8-15.

11 Holahan CJ, Pahl SA, Cronkite RC, et al. Depression and vulnerability to incident physical illness across 10 years. J Affect Disord 2010;123:222-9.

12 Knol M, Twisk J, Beekman A, et al. Depression as a risk factor for the onset of type 2 diabetes mellitus. A meta-analysis. Diabetologia 2006;49:837-45.

13 Golden SH, Lazo M, Carnethon $\mathrm{M}$, et al. Examining a bidirectional association between depressive symptoms and diabetes. JAMA 2008;299:2751-9.

14 Patten SB, Williams JV, Lavorato DH, et al. Major depression as a risk factor for chronic disease incidence: longitudinal analyses in a general population cohort. Gen Hosp Psychiatry 2008:30:407-13.

15 Blehar MC, Oren DA. Gender differences in depression. Med Gen Med 1997;2: 2-3.

16 Blazer DG, Kessler RC, McGonagle KA, et al. The prevalence and distribution of major depression in a national community sample: the National Comorbidity Survey. Am J Psychiatry 1994;151:979-86.

17 Courtenay WH. Behavioral factors associated with disease, injury, and death among men: evidence and implications for prevention.(statistical data included). J Mens Stud 2000;9:81-142.

18 Aneshensel CS. Marital and employment role-strain, social support, and depression among adult women. In: Hobfoll SE.ed. Stress, social support, and women. The series in clinical and community psychology; stress, social support, and women. Washington, DC, US: Hemisphere Publishing Corp, 1986:99-114.

19 Kessler RC. Epidemiology of women and depression. J Affect Disord 2003;74: 5-13.

20 O'Campo P, Eaton WW, Muntaner C. Labor market experience, work organization, gender inequalities and health status: results from a prospective analysis of US employed women. Soc Sci Med 2004;58:585-94.

21 Cornelius JR, Salloum IM, Mezzich J, et al. Disproportionate suicidality in patients with comorbid major depression and alcoholism. Am J Psychiatry 1995;152:358-64

22 McCusker J, Cole M, Ciampi A, et al. Major depression in older medical inpatients predicts poor physical and mental health status over 12 months. Gen Hosp Psychiatry 2007:29:340-8
23 Steele LS, Glazier RH, Lin $\mathrm{E}$, et al. Using administrative data to measure ambulatory mental health service provision in primary care. Med Care 2004:42:960-5.

24 Kessler RC, Andrews G, Mroczek D, et al. The World Health Organization Composite International Diagnostic Interview short-form (CIDI-SF). Int J Methods Psychiatr Res 1998;7:171-85.

25 American Psychiatric Association. Diagnostic and Statistical Manual of Mental Disorders. Washington, DC: American Psychiatric Association, 1994

26 Gershon AS, Wang C, Guan J, et al. Identifying patients with physician-diagnosed asthma in health administrative databases. Can Respir J 2009:16:183-8.

27 Gershon AS, Wang C, Guan J, et al. Identifying individuals with physician diagnosed COPD in health administrative databases. COPD 2009:6:388-94.

28 Tu K, Campbell NRC, Chen Z-L, et al. Accuracy of administrative databases in identifying patients with hypertension. Open Med 2007:1:1 e18-e26.

29 Hux JE, Ivis F, Flintoft V, et al. Diabetes in Ontario: determination of prevalence and incidence using a validated administrative data algorithm. Diabetes Care 2002:25:512-16

30 White $\mathrm{HL}, \mathrm{O}^{\prime} \mathrm{Campo} \mathrm{P}$, Moineddin $\mathrm{R}$, et al. Modeling the cumulative effects of social exposures on health: moving beyond disease-specific models. Int J Environ Res Public Health 2013;10:1186-201.

31 Matheson FI, White HL, Moineddin R, et al. Neighbourhood chronic stress and gender inequalities in hypertension among Canadian adults: a multilevel analysis. J Epidemiol Community Health 2010;64:705-13.

32 Health Statistics Division and Special Surveys Division SC. Canadian Community Health Survey (CCHS) cycle 1.1 derived variable (DV) specifications. Ottawa, Statistics Canada, 2003.

33 Reid R, MacWilliam L, Roos NP, et al. Measuring morbidity in populations: performance of the Johns Hopkins Adjusted Clinical Group (ACG) case-mix adjustment system in Manitoba. University of Manitoba, Manitoba Centre for Health Policy and Evaluation, 1999.

34 Courtenay WH. College men's health: an overview and a call to action. J Am Coll Health 1998:46:279.

35 Macintyre S, Hunt K, Sweeting $H$. Gender differences in health: are things really as simple as they seem? Soc Sci Med 1996;42:617-24.

36 Verbrugge LM. The twain meet: empirical explanations of sex differences in health and mortality. J Health Soc Behav 1989:30:282-304.

37 Rugulies R. Depression as a predictor for coronary heart disease. Am J Prev Med 2002;23:51-61.

38 Wulsin LR, Singal BM. Do depressive symptoms increase the risk for the onset of coronary disease? A systematic quantitative review. Psychosom Med 2003:65:201-10.

39 Ablon J. The nature of stigma and medical conditions. Epilepsy Behav 2002;36 Suppl 2):2-9.

40 Chan B. Atlas reports: supply of physicians' services in Ontario. Toronto: Institute for Clinical Evaluative Sciences, 1999. 